\title{
INTERAÇÕES TELECOLABORATIVAS NA APRENDIZAGEM DE LÍNGUAS ESTRANGEIRAS: FOCO NO USO DOS RECURSOS DO APLICATIVO COMPUTACIONAL OPENMEETINGS
}

\section{TELECOLLABORATIVE INTERACTIONS IN THE LEARNING OF FOREIGN LANGUAGES: FOCUS ON THE USE OF THE RESOURCES OF A WEB CONFERENCING SOFTWARE KNOWN AS OPENMEETINGS}

Francisco José Quaresma de Figueiredo Universidade Federal de Goiás - UFG

Suelene Vaz da Silva Instituto Federal de Educação, Ciência e Tecnologia de Goiás - IFG

\section{Resumo}

Este artigo apresenta um recorte de um estudo realizado entre aprendizes brasileiros e seus parceiros alemães que interagiram, em um contexto virtual, para aprender línguas e para desenvolver um projeto relacionado à sustentabilidade ambiental. A investigação qualitativa (BOGDAN; BIKLEN, 1994) foi conduzida

\begin{tabular}{|l|l|l|l|l|}
\hline Ilha do Desterro & Florianópolis & n 66 & p. 133- 171 & jan/jun 2014 \\
\hline
\end{tabular}


134 Francisco José Q. de Figueiredo and Suelene V. da Silva, Interações...

de agosto a dezembro de 2010. Os dados, coletados por meio de um aplicativo computacional denominado Openmeetings, foram analisados segundo, principalmente, as perspectivas teóricas da aprendizagem colaborativa de línguas e negociação (FIGUEIREDO, 2006; PICA, 1994) e aprendizagem de línguas em tandem/teletandem (BENEDETTI, 2010; TELLES, 2009a; VASSALO; TELLES, 2006, 2009). Os resultados discutidos, neste artigo, revelam como os interagentes congregam o uso dos recursos presentes no Openmeetings e os associados a ele para auxiliar seus parceiros na aprendizagem de português e inglês, bem como para discutir assuntos relacionado à temática do projeto proposto.

Palavras-chave: Aprendizagem de línguas; Openmeetings; Teletandem

\begin{abstract}
This paper is part of a study conducted among Brazilian learners and their German partners who interacted, through a virtual context, to learn languages and to develop a project on environmental sustainability. It is a qualitative research (BOGDAN; BIKLEN, 1994) conducted from August to December in 2010. The data, collected through a software called Openmeetings, were analyzed using mainly the theoretical perspectives of collaborative language learning and negotiation (FIGUEIREDO, 2006; PICA, 1994) and language learning in tandem/teletandem (BENEDETTI, 2010; TELLES, 2009a; VASSALO; TELLES, 2006, 2009). The results discussed in this paper show how the learners congregate the use of the features present in Openmeetings and other resources associated with it to help their partners in the learning of Portuguese and English, as well as to talk about issues related to the theme of the proposed project.
\end{abstract}

Key-words: Language learning; Openmeetings; Teletandem 


\section{Introdução}

O advento das Novas Tecnologias de Informação e Comunicação não só renovou bens de consumo, como também propagou uma necessidade vital de usufruí-los. Assim, produtos como a telefonia celular, a TV por assinatura, caixas bancários eletrônicos, redes de comunicação sem fio, o computador e a Internet tornaram-se bens constituintes da vida de muitas pessoas (FERNANDES; CONSOLO, 2010; LEFFA, 2006; TELLES, 2009b). A Internet, por exemplo, propicia a milhões de pessoas a oportunidade de interagir umas com as outras rotineiramente, rompendo fronteiras geográficas e redimensionando a percepção de espaço e de tempo. Essa rede de comunicação é, na sua essência, um ambiente propício à interatividade e, por conseguinte, à comunicação em outros idiomas (AIKEN; BALAN, 2011; CRYSTAL, 2001, 2003; PAIVA, 2001; WARSCHAUER, 1996).

A esse respeito, Warschauer (1996) afirma que a Internet oferece muitas vantagens para a aprendizagem de línguas. Dentre elas, (a) um ambiente mais autêntico, pois ouvir e ver combinam-se similarmente ao que ocorre no mundo real, (b) integração de um modo mais natural das habilidades de compreensão e de produção orais e escritas em razão dos recursos computacionais que o ambiente disponibiliza (áudio, chat, câmera de vídeo etc.), (c) controle do próprio processo de aprendizagem, já que os aprendizes, de certo modo, ditam o ritmo da atividade que estão desenvolvendo no ambiente virtual, e (d) possibilidade de trabalhar com a língua focando conteúdo, sem, no entanto, abandonar questões relacionadas a estruturas gramaticais.

No que concerne ao uso de tecnologias em contexto educacional, Höfling, Silva e Tosqui (2006) asseveram que recursos digitais podem facilitar o acesso a informações essenciais para o enriquecimento dos conhecimentos dos indivíduos envolvidos no processo de 
ensinar e de aprender uma língua estrangeira (LE). Para os autores, recursos como tradutores eletrônicos contribuem para o esclarecimento de dúvidas, principalmente dos significados de termos não muito usuais no contexto de aprendizagem de línguas do aprendiz. Contudo, há de se observar que traduzir de uma língua para outra é mais do que substituição de palavras, pois um computador não tem a compreensão de conceitos ou do significado das palavras em todos os contextos em que elas são utilizadas.

Silva (2012) acrescenta que a comunicação em ambientes virtuais ainda pode ser, em muitas situações, delimitada pela natureza do equipamento, pelas propriedades dos programas, bem como pelo servidor responsável ao acesso à rede. Essas limitações nem sempre são percebidas pelos usuários, que, segundo Crystal (2001), possuem altas expectativas de êxito no funcionamento do aparato tecnológico e certa carência de uma relação objetiva a respeito do funcionamento da internet. Nesse sentido, segundo o autor, é importante se considerar que o ritmo das interações virtuais é mais lento do que nas situações presenciais, pois depende do equipamento, dos programas, das circunstâncias, do hábito e da personalidade dos usuários. Crystal (2001) afirma que a maioria dos usuários tolera, em interações síncronas, uma demora para receber uma resposta à sua mensagem de em torno de 2 a 4 segundos, e demoras de mais de 5 segundos podem causar-lhes frustrações. Além do mais, o silêncio pode gerar ambiguidade tanto para o emissor quanto para o receptor, pois não há como de fato saber se a mensagem chegou ao receptor ou se ele está encontrando problemas para compreendê-la ou se optou por não responder a ela de imediato ou se está pensando na melhor maneira de responder à mensagem.

As ferramentas tecnológicas, como postula Crystal (2003), enriquecem os processos de ensino e aprendizagem de LE não somente 
pelos próprios recursos inerentes ao meio digital, mas também por possibilitar aos alunos compartilhar conhecimento e, por conseguinte, aprender línguas uns com os outros, ou seja, permite aos aprendizes trabalhar colaborativamente.

Esse trabalho colaborativo eflui da abordagem colaborativa de aprendizagem de línguas. Essa abordagem baseia-se na teoria sociocultural que tem por premissa o fato de que a aprendizagem ocorre dentro e a partir de interações significativas pelas quais os indivíduos coconstroem conhecimento (DONATO; MCCORMICK, 1994; FIGUEIREDO, 2006; VYGOTSKY, 1981, 1998).

Swain (1999) aponta cinco aspectos favoráveis ao engajamento dos aprendizes em atividades colaborativas: (1) encoraja a participação ativa dos aprendizes na construção da tarefa, já que eles precisam trabalhar em pares ou em grupos; (2) favorece o foco na forma, pois os aprendizes buscam expressar o conteúdo de modo correto, coerente e apropriado; (3) possibilita aos aprendizes perceber as lacunas em relação ao próprio conhecimento linguístico, pois, enquanto tentam expressar os significados que desejam, eles reestruturam a produção linguística e testam hipóteses em busca de soluções; (4) favorece externalizar o conhecimento, o que lhes permite refletir sobre ele, revisá-lo e aplicá-lo e (5) requer um produto final, que pode ser, por exemplo, um texto escrito ou uma apresentação oral. A autora ainda acrescenta que tarefas colaborativas são comunicativas e, portanto, propiciam aos aprendizes negociar tanto sobre a forma quanto sobre o conteúdo da língua, além de estreitar laços de amizade.

A negociação é um tipo de interação que "caracteriza a modificação e a reestruturação da interação que ocorre quando os aprendizes e seus interlocutores antecipam, percebem ou experienciam dificuldades na compreensão da mensagem" (PICA, 1994, p. 494). Essa negociação tem a intenção de tornar a mensagem compreensí- 
vel nos dois sentidos: tanto aquela que o aprendiz produz, o output, quanto a que é dirigida a ele, o input. Dessa forma, segundo a autora, o aprendiz, para se fazer entender, repete a mensagem literalmente, faz ajustes na sintaxe, troca termos ou modifica a estrutura e o significado de diversas maneiras. De acordo com Pica (1994) e Swain (1997, 2000), o output é necessário para que a aprendizagem da LE ocorra, pois, ao produzir na LE, o aprendiz também amplia as oportunidades para compreender e internalizar, além do sentido da mensagem, a estrutura linguística da língua. Segundo Santos (2009, p. 130), “[q]uanto mais altos os índices de negociabilidade, mais recorrente, enriquecida e diversificada pode ser a oferta de insumo e mais favorável à aprendizagem se torna o trabalho colaborativo". O autor acrescenta que a percepção na incompreensão na mensagem constitui a mola propulsora para o processamento e o reprocessamento das informações linguísticas na construção individual e colaborativa da aprendizagem.

Figueiredo (2006) acrescenta que a aprendizagem colaborativa possibilita aos aprendizes discutir, argumentar, apresentar seus pontos de vista, bem como ouvir os dos colegas. Assim, por meio de interações, reflexões e inquietações, eles vão delineando a própria aprendizagem. É no processo da interação que os aprendizes definem seus papéis, compartilham as línguas e as culturas e, com o auxílio do outro, colaborativamente transformam suas experiências em estruturas de conhecimento. Em contextos virtuais, esse auxílio pode ocorrer por meio de ferramentas técnicas, como os recursos disponibilizados pelo computador e pela Internet. Fernandes e Consolo (2010) também corroboram a ideia de que o ensino de LE pode beneficiar-se dos recursos presentes nos ambientes virtuais, visto serem estes ambientes propícios a interações colaborativas.

Um uso inovador dos recursos digitais a favor da aprendizagem colaborativa de línguas ocorre na modalidade tandem de aprendi- 
zagem de línguas. O vocábulo tandem, originalmente, nomeia um tipo de bicicleta que possui dois ou mais assentos (tandem bicycle) e significa, por extensão, o esforço mútuo de duas ou mais pessoas para realizarem juntas uma atividade, ou seja, colocar a bicicleta em movimento (SOUZA, 2003, 2006). No ensino de línguas, esse vocábulo está relacionado a uma forma de aprendizagem baseada em comunicação autêntica e colaborativa que se configurou, ao longo do tempo, como aberta, por não seguir um programa curricular fixo; intercultural, por envolver diferentes línguas e culturas; interpessoal, por ser praticada por pares de aprendizes; socialmente simétrica, por promover a alternância de papéis, de aprendizes e de auxiliares na aprendizagem do outro; e criativa, por suscitar a livre exploração da criatividade (BENEDETTI, 2010; VASSALO; TELLES, 2006; TELLES, 2009a).

No Brasil, a UNESP (Universidade Estadual de São Paulo) - Campi Assis e São José do Rio Preto - é a instituição de ensino pioneira na utilização dessa modalidade de aprendizagem em larga escala. O projeto desenvolvido por essa universidade renomeou a modalidade de aprendizagem de línguas em tandem para teletandem. Segundo a equipe de linguistas aplicados do Campus de São José do Rio Preto, teletandem é o tandem

realizado em um contexto virtual, assistido pelo computador, à distância, via comunicação síncrona, por meio da utilização dos recursos de escrita, leitura, e videoconferência de aplicativos de mensagens instantâneas (Skype, Windows Live Messenger, Oovoo, e Talk and Write, por exemplo). (TELLES, 2009a, p. 17)

A esse construto, Vassallo e Telles (2009, p. 21) acrescentam que as sessões de teletandem envolvem "encontros estabelecidos em consenso por dois falantes de diferentes línguas que não são necessaria- 
mente nem nativos, nem professores com licenciatura. Ambos estão interessados em estudar a língua estrangeira na qual o outro é mais proficiente".

O teletandem sustenta-se em três princípios básicos: (1) princípio da separação de línguas - cada língua possui o seu momento apropriado de prática durante a sessão de interação; (2) princípio da reciprocidade - cada um dos membros do par se compromete em auxiliar o parceiro na aprendizagem da língua-alvo, invertendo, conforme definição do par, a língua a ser utilizada na interação e, por conseguinte, o papel de auxiliar; e (3) princípio da autonomia - cada um dos interagentes é responsável por definir e gerenciar o seu próprio processo de aprendizagem (CAVALARI, 2010; SILVA, 2012; TELLES, 2009a). Vassallo e Telles (2009, p. 24, grifo dos autores) acrescentam que "os parceiros do tandem são livres para decidirem sobre o quê, quando, onde e como estudar e, também, por quanto tempo desejam fazê-lo." Porém, os autores nos alertam sobre o fato de que a autonomia, em contexto de tandem, não pode ser interpretada como fazer sozinho, mas, como um fazer em colaboração com o outro. Nesse sentido, os parceiros agem como membros de uma equipe, cujas ações e atitudes individuais são complementadas pelas do outro, constituindo, desse modo, uma identidade de parceria. Benedetti (2010) acrescenta que, em aprendizagem em teletandem, os parceiros assumem o compromisso com a própria aprendizagem, bem como em auxiliar o outro na aprendizagem da língua de sua competência. A autora acrescenta ainda que a escolha do aplicativo para realizar as sessões de interação em teletandem e o modo como ele é usado pelos participantes podem influenciar a forma como a interação irá se desenvolver.

Vassallo (2009) complementa o exposto por Benedetti (2010) e afirma que os recursos dos aplicativos computacionais podem possi- 
bilitar aos interagentes: escrever e falar ao mesmo tempo, já que teclado e microfone podem ser utilizados concomitantemente, tornando-se a escrita um complemento para a fala ou vice-versa; usar apenas alguns dos recursos (por escolha ou por falta de opção), como ler e escrever, sem fazer uso do áudio, o que pode favorecer a prática da escrita; e fazer uso de webcams para ver simultaneamente a própria imagem e a do parceiro.

Este estudo busca, portanto, averiguar a viabilidade do aplicativo computacional de mensageira instantânea Openmeetings na realização de sessões de interação em teletandem, bem como compreender o uso que os participantes fizeram dos recursos integrados e associados a esse aplicativo no processo de aprendizagem de línguas estrangeiras.

\section{2. $O$ estudo}

Esta investigação qualitativa (BOGDAN; BIKLEN, 1994) contou com a parceria de três instituições de ensino superior: o Instituto Federal de Educação, Ciência e Tecnologia do Estado de Goiás (IFG), Campus Goiânia, e duas instituições alemãs, a Universidade de Trier e a Universidade de Ciências Aplicadas de Worms.

A parceria entre essas universidades foi feita para que os aprendizes pudessem, por meio de interações telecolaborativas, aprender a língua de proficiência uns dos outros, bem como trocar ideias a respeito de um projeto que iriam desenvolver sobre sustentabilidade, visto ser este um tema de interesse comum entre as instituições envolvidas na pesquisa. Dessa parceria, participaram 12 pares de interagentes. É importante ressaltar que, antes de os interagentes iniciarem efetivamente as interações, houve uma série de passos para a seleção dos participantes. Recebemos uma lista com o nome 
142 Francisco José Q. de Figueiredo and Suelene V. da Silva, Interações...

de 12 aprendizes estrangeiros que se voluntariaram a compor parcerias com os aprendizes brasileiros para, juntos, participarem das sessões de teletandem. Houve também uma lista de aprendizes brasileiros com cerca de 30 voluntários. Dessa lista, foram selecionados os 12 primeiros que se inscreveram para formar as parcerias com os aprendizes estrangeiros. De posse dessas listas, foi feito um primeiro contato por email para que os participantes pudessem definir com quem iriam estabelecer as parcerias e sugerir dias e horários para a primeira interação entre eles. Posteriormente, as duplas de interagentes se encarregaram de agendar as sessões de interação seguintes, de acordo com a disponibilidade de cada um.

Por razões de espaço, para ilustrar este estudo, serão apresentados dados de apenas cinco pares de interagentes compostos por cinco brasileiros - sendo 4 estudantes e uma professora da Instituição que desejavam aprender ou aprimorar seus conhecimentos da língua inglesa - e quatro alunos da Universidade de Worms e um aluno da Universidade de Trier. O quadro, a seguir, apresenta os pares de interagentes, bem como o nível de escolaridade e a área de estudo de cada um deles, identificados pelos pseudônimos por eles escolhidos e as parcerias constituídas para as interações, que foram transcritas verbatim.

QUADRO 1: Os participantes brasileiros e estrangeiros

\begin{tabular}{|l|l|l|l|l|}
\hline \multicolumn{2}{|c|}{ Aprendizes brasileiros } & \multicolumn{2}{|l|}{ Aprendizes alemães } \\
\hline $\mathbf{1}$ & Drica & $\begin{array}{l}\text { Coordenadora e } \\
\text { professora dos Cursos } \\
\text { Superiores Tecnológi- } \\
\text { cos em Turismo e em } \\
\text { Hotelaria }\end{array}$ & Red & $\begin{array}{l}\text { Aluna do Mestrado } \\
\text { em Gestão de Tur- } \\
\text { ismo Internacional } \\
\text { em Worms, de nacio- } \\
\text { nalidade romena, mas } \\
\text { pertencente ao grupo } \\
\text { de alunos alemães }\end{array}$ \\
\hline
\end{tabular}




\begin{tabular}{|c|c|c|c|c|}
\hline 2 & Gustavo & $\begin{array}{l}\text { Aluno do } 5^{\circ} \text { período } \\
\text { do Curso Superior Tec- } \\
\text { nológico em Hotelaria }\end{array}$ & Lini & $\begin{array}{l}\text { Aluna do Bachare- } \\
\text { lado em Turismo e } \\
\text { Gestão de Viagens em } \\
\text { Worms }\end{array}$ \\
\hline 3 & Jujuba & $\begin{array}{l}\text { Aluna do } 4^{\circ} \text { período } \\
\text { do Curso Superior Tec- } \\
\text { nológico em Turismo }\end{array}$ & $\begin{array}{l}\text { Pere- } \\
\text { grino }\end{array}$ & $\begin{array}{l}\text { Aluno do Mestrado } \\
\text { em Planejamento } \\
\text { Ambiental em Trier }\end{array}$ \\
\hline 4 & Natalie & $\begin{array}{l}\text { Aluna do } 6^{\circ} \text { período } \\
\text { do Curso Superior Tec- } \\
\text { nológico em Turismo }\end{array}$ & Teego & $\begin{array}{l}\text { Aluno do Mestrado } \\
\text { em Gestão de Tur- } \\
\text { ismo Internacional } \\
\text { em Worms }\end{array}$ \\
\hline 5 & Nath & $\begin{array}{l}\text { Aluna do } 4^{\circ} \text { período } \\
\text { do Curso Superior Tec- } \\
\text { nológico em Turismo }\end{array}$ & Eve & $\begin{array}{l}\text { Aluna do Bachare- } \\
\text { lado em Turismo e } \\
\text { Gestão de Viagens em } \\
\text { Worms }\end{array}$ \\
\hline
\end{tabular}

É preciso esclarecer que, no IFG, as línguas estrangeiras estudadas são o inglês, o espanhol e o francês. Como os participantes brasileiros desejavam aprimorar o seu conhecimento de língua inglesa, esta foi a língua escolhida por eles para ser a trabalhada juntamente com o português nas interações. Assim, os participantes brasileiros auxiliaram seus parceiros na aprendizagem do português e receberam auxílio destes na aprendizagem da língua inglesa, visto que os alunos das universidades alemãs eram proficientes nessa língua. É importante ressaltar também que os interagentes estrangeiros visitaram o Brasil, especificamente o estado de Goiás, com o intuito de encontrarem seus parceiros brasileiros e juntos terminar o projeto relacionado à sustentabilidade, sobre o qual puderam discutir virtualmente.

Para propiciar a interação entre os participantes brasileiros e estrangeiros, foi utilizada a mensageira síncrona gratuita denominada Openmeetings, por ser o aplicativo utilizado pelo IFG para realizar videoconferências. Esse aplicativo permite conferência através de proto- 
144 Francisco José Q. de Figueiredo and Suelene V. da Silva, Interações...

colo web, com o uso de um simples navegador, como Internet Explorer, Firefox ou Google Chrome. O Openmeetings é integrado ao Moodle e, desse modo, o acesso se dá exatamente da mesma forma como ocorre para um fórum, um chat ou qualquer outro recurso do Moodle.

Para acessar o aplicativo, o usuário precisa de um computador conectado à rede por um modem ADSL (Asymmetric Digital Subscriber Line). A figura, a seguir, apresenta a sala de interação do Openmeetings.

FIGURA 1: Sala de interação do aplicativo Openmeetings

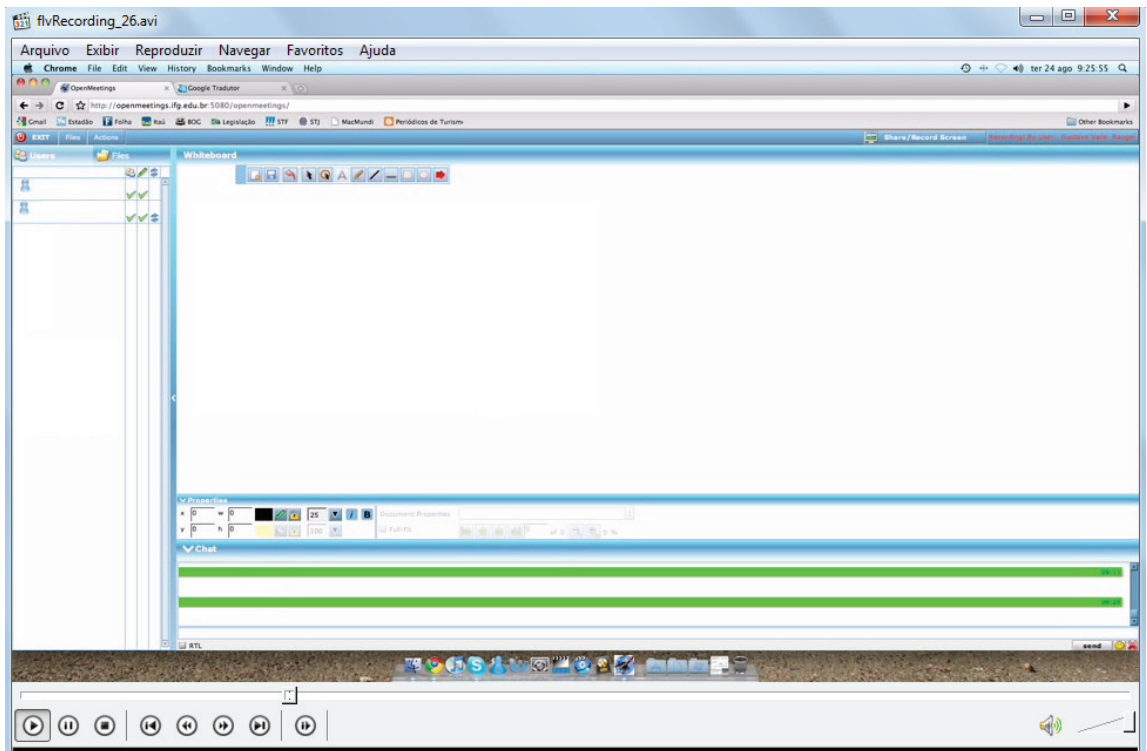

O aplicativo permite teleconferência com os seguintes componentes e funções integrados:

- gerenciamento de permissões - caso haja muitos participantes, um deles pode assumir o papel de moderador e controlar as per- 
missões dos outros usuários, inclusive nomear um deles para também desempenhar o papel de moderador;

- compartilhamento de tela - compartilhamento entre os usuários das telas dos monitores para apresentar qualquer informação que nelas apareça;

- manipulação remota - o moderador pode autorizar que o outro usuário manipule sua tela. Caso haja mais de dois usuários, enquanto a tela é utilizada, ela ainda pode ser compartilhada com os demais participantes;

- gravação de apresentação - apresentações de arquivos, bem como compartilhamento da tela do monitor e da lousa interativa podem ser salvas e gravadas para posterior distribuição do arquivo de gravação;

- chat - interação por meio de mecanismo de chat textual;

- áudio - interação verbal através de microfone, desde que o usuário que desempenhe o papel de moderador dê tal permissão;

- vídeo - interação por meio de imagem via webcam;

- lousa interativa - uso da lousa para apresentar esquemas gráficos, digitar texto, rabiscar, desenhar, postar fotos etc.;

- apresentação de arquivos enquanto os usuários interagem através de chat, áudio, vídeo e lousa - exposição de PDF (Portable Document Format) e de PPT (Power Point Templates). 
146 Francisco José Q. de Figueiredo and Suelene V. da Silva, Interações...

Finalizamos a apresentação desse aplicativo ressaltando que o Openmeetings possibilita a gravação de áudio e de vídeo em formato AVI (Audio Video Interleave) ou FLV (Flash Video). Os arquivos de gravação ficam armazenados no próprio aplicativo e podem ser salvos para uso posterior, o que favorece o uso desse aplicativo em pesquisas relacionadas à aprendizagem de línguas em teletandem.

\section{Discussão dos dados}

Neste estudo, os recursos presentes no aplicativo Openmeetings - tais como áudio, chat, vídeo e lousa interativa - e os associados a ele apresentaram-se como recursos bastante positivos para auxiliar a interação dos aprendizes no meio virtual. Nesse sentido, como nos mostram os diálogos a seguir, a mixagem de áudio, vídeo, chat, lousa interativa, bem como de tradutores e dicionários eletrônicos, permitiu aos interagentes fazer uso de diferentes recursos de comunicação, o que ocasionou a oferta praticamente simultânea de input oral e escrito.

No recorte a seguir, os aprendizes Natalie e Teego conversam sobre um aluno alemão da universidade de Trier que estava no IFG cumprindo um programa de intercâmbio. Natalie comenta com Teego que ambas as Universidades, Trier e Worms, apresentam a mesma rotina acadêmica. Teego não compreende o termo 'routine', utilizado por Natalie, provavelmente pelo modo como ela o pronunciou. Ela, então, utiliza-se da escrita, por meio do chat, para ilustrar a pronúncia do termo que causara lacuna na compreensão da mensagem. Assim, fala e escrita são dois recursos disponíveis no aplicativo, que, na interação, se tornam complementares, auxiliando os alunos a compreender e a se fazer compreendidos. 
[1]

[Interação via Openmeetings - 26/08/2010]

Teego: Yep, we don't have, like, a contact.

Natalie: What?

Teego: We don't really have a contact with each other, like...

Natalie: Yes, he said this too. But is the same 'routine', the both Universities ((tonicidade depositada em 'rou')).

Teego: I don't understand that one.

Natalie: What?

Teego: Can you repeat that one again?

Natalie: It is the same 'routine.' 'Routine'. (tonicidade depositada em 'rou').

Natalie: [Chat] routine

Teego: Same 'routine'? ((tonicidade depositada em 'ti')).

Natalie: Yes, 'routine' ((tonicidade depositada em 'rou')).

Teego: Ok. Yep.

Natalie: Yep. It is the same, because they stay in the University, he stay in the University all the day and when they are in holiday they pass with his parents.

Como podemos perceber por meio desse exemplo, a mixagem de áudio e de chat proporciona aos alunos, em contexto virtual de aprendizagem de línguas, dois canais de comunicação praticamente concomitantes. A pronúncia do termo 'routine’ pelos dois interagentes, com tonicidades diferentes, causou incompreensão na mensagem. Natalie, então, ao invés de esclarecer o significado do termo, como geralmente ocorre nas negociações de significado, segundo Swain $(1999,2000)$, opta por não reestruturar o output. Ela troca o canal de vinculação da mensagem, passando de áudio a escrita, o que possibilitou a compreensão da mensagem por seu par. 
148 Francisco José Q. de Figueiredo and Suelene V. da Silva, Interações...

No recorte 2, apresentamos um diálogo entre as interagentes Drica e Red, em que a interagente romena diz a sua parceira brasileira que está muito interessada nos tipos de comida servida nas refeições em Goiás. Drica, então, menciona três tipos de comidas usuais na mesa goiana, 'pequi com arroz ou com frango', 'churrasco' e 'feijoada'. Ela usa o termo correspondente a 'churrasco' em inglês para que Red identifique o prato. Para os outros dois pratos, Drica menciona os principais ingredientes 'pequi' e 'feijão'. Então, enquanto Drica pronuncia 'churrasco,' 'pequi' e 'feijão', ela escreve essas palavras, oferecendo a Red o registro escrito, utilizando-se, portanto, de mais um recurso para que a parceira alemã possa compreender a mensagem.

[Interação via Openmeetings - 30/08/2010]

Drica: And 'pequi' is a fruit that we eat with rice, we eat rice, we eat rice every day here, 'beans', eh, 'beans' too and a lot of vegetables, we have a lot of fruits, so we have a nice, a nice food here $[. .$.

Drica: [Chat] Churrasco

Red: [Chat] ok

Drica: We have too, 'feijoada'

Drica: 'Feijoada' (escreve enquanto fala) [Chat] Feijoada

Drica: Do you know 'feijoada'? Eh, 'feijoada', eh, 'feijão, feijão'.

Drica: 'Feijão' (escreve enquanto fala) [Chat] Feijão

Drica: 'Bean, bean'? É, 'beans'

Drica: 'Beans' (escreve enquanto fala) [Chat] Beans

Drica: 'Beans', ah, it's a food come from, hã, Africa and... Africa and Arabian people. I don't know why my... wait a minute.

Red: [Chat] German Feijão - Bohnen 
Esse exemplo ilustra o uso quase que simultâneo, por parte dos interagentes, do som, da grafia e da explicação do significado das palavras que estão sendo aprendidas. A opção por recursos variados (chat e áudio) corrobora as afirmações de Benedetti (2010) e de Vassalo e Telles (2009) de que o teletandem suscita o uso da criatividade, que pode ser explorada pelo uso das ferramentas oferecidas, por exemplo, pelo Openmeetings.

Natalie e Teego, diferentemente de Drica e Red, optam por trabalhar com escrita e oralidade sequencialmente. Eles primeiramente praticam o som das palavras para depois enviar ao parceiro a grafia, ilustrando a pronúncia do termo. No recorte 3 , o par conversava sobre a viagem que Teego faria ao Brasil, particularmente sobre alguns parentes do interagente que vivem em São Paulo. $\mathrm{O}$ assunto leva o par a trabalhar com alguns vocábulos referentes a membros da família. Natalie inicia pela palavra 'mãe', como nos mostra o exemplo a seguir.

[Interação via Openmeetings - 28/08/2010]

Natalie: Yes, yes, it is. You want to learn how pronounce the name of the relatives in Portuguese?

Teego: Yes, I would like to, yeah.

Natalie: Yes. 'Mother' is 'mãe'.

Natalie: [Chat] mãe

Teego: How do you pronounce it?

Natalie: 'Mãe'.

Teego: 'Mãe. Mãe, mãe, mãe'.

Natalie: Or if you want to, like me, I pronounce like a ... some child pronounce like this... But is a very ... with love, very carefully way to say: 'mamãe'. 
Natalie: [Chat] mamãe

Teego: 'Mamãe’.

Natalie: Yes? Yes, 'mamãe' is more cute.

Teego: Yep. Ok.

O chat, utilizado como ferramenta auxiliar à fala, demonstra a dinamicidade entre oralidade e escrita nas interações em teletandem via Openmeetings. A combinação da escrita e da fala não só propicia aos interagentes mais recursos para a aprendizagem de LE, como também evidencia a autonomia deles. Nesse sentido, quando o interagente opta por um recurso ou por outro, ele apresenta uma autonomia que reflete a responsabilidade para com a própria aprendizagem, bem como para com a de seu par, conforme postulam Vassalo e Telles $(2006,2009)$. Assim, o chat, usado antes ou depois da fala, facilita a compreensão da língua que o parceiro está aprendendo.

$\mathrm{O}$ uso do chat também ocorreu, neste estudo, quando um dos interagentes explicitamente solicita a seu par que escreva o termo que está sendo o foco da aprendizagem. No recorte a seguir, apresentamos um diálogo em que Natalie auxiliava Teego na produção do cumprimento 'bom dia' em português. Teego, após ouvir a pronúncia, manifesta que preferiria ver a forma escrita enquanto pratica a oralidade. Natalie atende de imediato à solicitação de seu par e envia-lhe por chat 'bom dia = good morning'. Teego, como já ocorrera com Drica e Natalie nos exemplos anteriores, associa a grafia da palavra com a pronúncia, como podemos observar a seguir.

[Interação via Openmeetings - 26/08/2010]

Natalie: Yes, thank you. So... oh, we can learn Portuguese? We can start? 
Teego: Yes. I think we can start, yes?

Natalie: Can start with the simple, simple things, simple phrases, like 'good morning', 'good afternoon', like I said yesterday, can be?

Teego: Could be great!

Natalie: 'Good morning' is 'bom dia'.

Teego: Could you perhaps write it as well? So, I can see and speak.

Natalie: [Chat] bom dia = good morning

Teego: It is perfect.

Natalie: Yep.

Teego: So, it was spoken like. What? 'Good morning' is? How do you pronounce it?

Natalie: 'Bom dia'.

Teego: With a big 'm'. 'Bom dia'.

Natalie: 'Bom dia'.

Teego: 'Bom dia'.

Natalie: Yes, this is good.

Teego: 'Bom dia'. 'Bom dia', Natalie.

Natalie: Very nice, very nice.

No recorte seguinte, Teego novamente solicita a Natalie a grafia de um termo para, por meio da visualização da escrita, compreender a mensagem. Neste recorte, o par, em vias de encerrar a sessão de interação, comentava sobre o local e o horário da próxima interação quando Teego, ao fazer o comentário 'Same time, same place', remete, Natalie ao seriado mexicano 'Chaves', exibido por uma rede brasileira de televisão. Nesse seriado, ao final de cada episódio, o personagem principal, que possui o mesmo nome do seriado, alerta os telespectadores para não perderem o próximo episódio na mesma hora e no mesmo canal. Natalie, então, na tentativa de conduzir Tee- 
152 Francisco José Q. de Figueiredo and Suelene V. da Silva, Interações...

go à compreensão de qual tipo de programa ela se referia, inicia um processo de negociação, conforme podemos conferir a seguir.

[5]

[Interação via Openmeetings - 28/08/2010]

Teego: 'Same time, same place'.

Natalie: 'Same place', no, not 'same place', because today I'm home.

Teego: Yes, but for me is the 'same place'.

Natalie: Yes, yes. Like 'Chaves', yes, do you know 'Chaves, Chaves'?

Teego: No.

Natalie: Hum, the Mexican, hum, 'serie', I don't know, I have to check 'Mexican serie' (pronuncia 'serie' de modo similar a LP) Teego: Write it.

Natalie: Hum... just a moment.

Teego: Ok, no problem.

Natalie: [Chat] Chaves

Natalie: 'Chaves', Argentina or Mexico, I don't remember now. It is a old 'serie' (novamente a pronúncia se assemelha à LP).

Teego: Actually I don't think I know it.

Natalie: You don't know?

Natalie: [Chat] serie

Teego: Is it, like, a name of the 'serie', of a 'serie'?

Natalie: Yes, yes, is the name.

Teego: I think, I don't know.

Natalie: É uma 'série'. When you came to Brazil I will show to you, is very common here.

Teego: Ok. 
O processo de negociação de Natalie envolve novamente o áudio e o chat. Contudo, desta vez, a opção de Natalie de enviar, por escrito, o termo "Chaves' não auxilia Teego na solução da incompreensão da mensagem. Nesse sentido, a ilustração do termo por meio do chat não foi suficiente para resolver o problema, já que ele não conhecia o seriado a que sua parceira se referia. Somente após ela enviar-lhe o termo 'serie' é que Teego compreende do que se tratava o assunto. Porém, sendo o seriado desconhecido para ele, a compreensão da mensagem torna-se parcial. Natalie decide, então, adiar a compreensão do assunto para quando Teego estiver no Brasil e puder assistir ao seriado e, assim, compreender o porquê de ela ter associado a fala dele ao personagem 'Chaves'.

A negociação do par Teego e Natalie deixa claro que algumas mensagens para serem compreendidas dependem também de outras informações, como, por exemplo, do compartilhamento de conhecimento que seja comum aos interagentes, caso contrário o uso conjugado de áudio e chat pode não ser suficiente para resolver a incompreensão da mensagem. Nesse sentido, Santos (2009) afirma que a colaboração é bem mais frutífera quando há mais negociação e, por conseguinte, mais oferta variada de input. Entretanto, como a aprendizagem em teletandem segue o princípio de autonomia, são os interagentes que definem de que forma vão desenvolver o processo de negociação. No caso desse recorte, o interagente teria a oportunidade de complementar sua compreensão do assunto em questão quando estivesse no Brasil, mas, geralmente, essa não é a realidade dos pares que se engajam na aprendizagem de línguas em teletandem.

No diálogo seguinte, Natalie explicitamente oferece a forma escrita ao seu par Teego. Ao conversar sobre o que fariam naquela noite, Natalie diz a Teego que sairia com alguns amigos para comemorar o aniversário de um deles. Teego pede a ela que lhe transmita os seus 
154 Francisco José Q. de Figueiredo and Suelene V. da Silva, Interações...

cumprimentos e inicia um processo de negociação para aprender como falar 'feliz aniversário' em português. Primeiramente, ele faz uma pergunta direta 'How do you say happy birthday in Portuguese?'. Natalie responde referindo-se apenas ao termo 'aniversário' e envia esse termo a Teego por chat. Logo após, ela novamente usa o chat para esclarecer a dúvida de Teego dos termos 'feliz aniversário' empregados juntos, como nos mostra o diálogo entre o par.

[6]

[Interação via Openmeetings - 28/08/2010]

Teego: How do you say 'happy birthday' in Portuguese?

Natalie: Ah, ok, 'aniversário'. I will write to you.

Natalie: [Chat] aniversário

Teego: Thank you.

Natalie: Yes, 'aniversário'.

Teego: and 'happy', is not necessary?

Natalie: Yes, if you want to do congratulations to a people is 'feliz aniversário'.

Natalie: [Chat] feliz aniversário

Teego: Ah, ok. 'Feliz aniversário'.

Natalie, ciente de que o chat é um recurso auxiliar útil à compreensão das mensagens por seu parceiro, já lhe oferece esse recurso, ao dizer 'I will write to you'. Os exemplos até aqui apresentados demonstram que Natalie, Teego, Drica e Red percebem o uso dos recursos do aplicativo Openmeetings - áudio e chat - frutífero para a aprendizagem de línguas em teletandem.

A lousa interativa - outro recurso disponibilizado no aplicativo Openmeetings - também se apresentou com um apoio auxiliar à comunicação durante as interações ocorridas no ambiente virtual, por 
meio da qual o interagente podia postar fotos, desenhar, ou simplesmente escrever, como se fosse em um quadro de sala de aula.

$\mathrm{Na}$ interação ilustrada no excerto 7, Peregrino utiliza a lousa interativa para ilustrar, para sua parceira, o assunto da interação. Os interagentes estavam conversando sobre um projeto que deveriam desenvolver sobre sustentabilidade. Peregrino usa a lousa interativa para explicar à sua parceira o conceito de 'emissão de carbono'. Para tanto, ele desenha primeiramente retângulos com as palavras 'before' e 'after', representando a medição do nível de emissão de carbono antes e depois da realização de alguma ação redutora da emissão do componente químico, conforme nos mostra a ilustração da lousa, seguida pelo diálogo.

[7]

[Interação via Openmeetings - 03/09/2010]

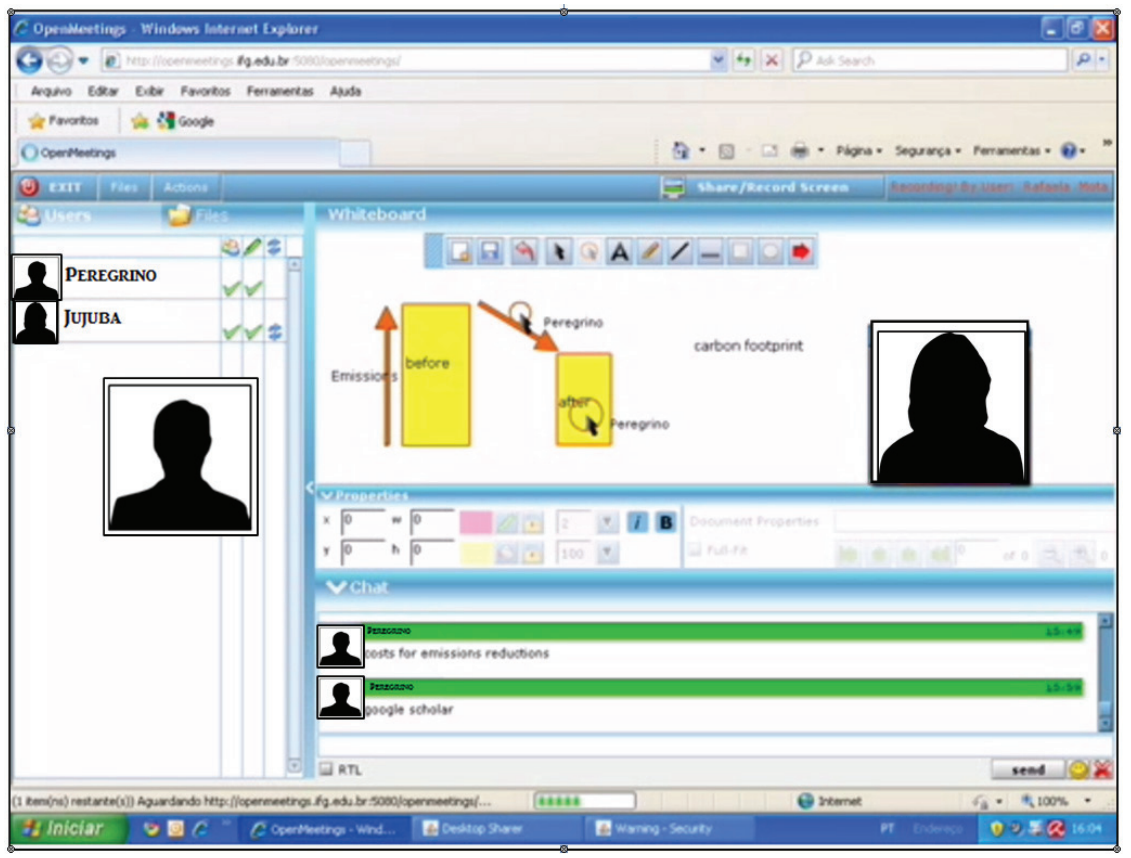


156 Francisco José Q. de Figueiredo and Suelene V. da Silva, Interações...

Jujuba: Emission...

Peregrino: Do you see on the whiteboard? Like this one would be a normal and you have another scenario, just like this, so you have a reduction here to here, and this reduction, hã, costs something ((Peregrino vai desenhando na lousa interativa enquanto explica sobre a redução)).

Jujuba: Hum, ok.

Peregrino: This is a, emission to for... for, because for the climate change, you have to reduce the emissions, right? What about this?

Jujuba: Ok.

No exemplo 8, Gustavo está auxiliando sua parceira na aprendizagem do português. O tema da interação é o uso de tempos verbais em português. Eles começam a falar sobre o tempo 'passado' e, posteriormente, falam sobre como se expressar usando o tempo verbal 'futuro'. A lousa interativa, tal como o chat, é usada por esse interagente para ilustrar, por escrito, a conjugação verbal discutida na interação.

[8]

[Interação via Openmeetings - 28/08/2010]

Gustavo: O plural, Lini. O plural é isso aqui, olha... O plural seria assim... O plural seria esse, olha... 'vocês foram'.

Lini: Hum.

Gustavo: 'Vocês foram'.

Lini: E 'nós'?

Gustavo: Nós? 'Nós fomos'.

Lini: 'Nós fomos'.

Gustavo: Very good! 'Nós fomos'.

Lini: 'Fomos'. 
Gustavo: Muito bem, Lini. E para falar no futuro. Para falar sobre o futuro, in the future tense, é muito simples, você pode falar assim, olha, for example, eu, 'eu vou comer', 'eu vou comer'. Eu... Lini: Como em espanhol? Ah, eu vou. Unhum.

Gustavo: Exactly. Like I'm going to, I'm going to. Eu vou, aah, dormir... I think you won't have problems with this.

Lini: 'Eu vou comer'. 'Eu vou dormir'.

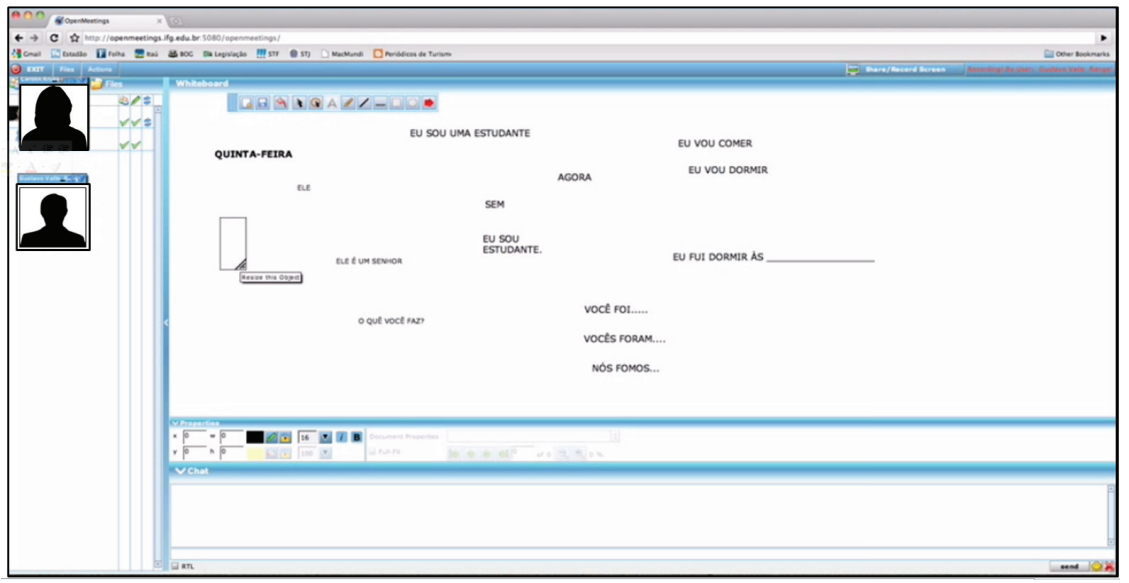

Além do áudio, do chat e da lousa interativa, outros recursos digitais, como os tradutores e dicionários eletrônicos tornam-se ferramentas de que os aprendizes lançam mão em busca de auxílio para a sua própria aprendizagem. Em contexto de interação via aplicativo de mensageira instantânea, o modo como se faz uso dessas ferramentas pode interferir no desenvolvimento do processo de aprendizagem de línguas. Nessa perspectiva, apresentamos, a seguir, o uso que alguns interagentes de nosso estudo fizeram dos recursos Google Translator e dicionários on-line ao associá-las ao aplicativo Openmeetings durante as interações em teletandem. 
158 Francisco José Q. de Figueiredo and Suelene V. da Silva, Interações...

O exemplo seguinte é um recorte da interação entre Nath e Eve, na qual as interagentes conversam sobre trabalho. Nath diz a Eve que trabalha na faculdade e abre a janela do Google Translator para traduzir do português para o inglês os termos 'laboratório', 'universidade' e 'laboratório de eventos', mas acaba utilizando apenas 'lab of events' para especificar o local onde trabalha. Ao ser perguntada sobre as funções que desempenha, Nath novamente utiliza o tradutor em busca de auxílio para elaborar a sua fala, contudo ao receber a resposta do tradutor eletrônico, Nath modifica o input antes de enviá-lo a Eve. Esse uso que Nath fez do tradutor eletrônico corrobora as colocações de Höfling, Silva e Tosqui (2006) sobre o uso de ferramentas como tradutores eletrônicos. Para esses autores, esses recursos contribuem para o esclarecimento de dúvidas, principalmente dos significados de termos que os aprendizes desconhecem. No entanto, os autores afirmam que traduções realizadas por máquinas apresentam limitações, pois as informações que os programas computacionais de tradução geralmente possuem não possibilitam a esses programas ir muito além do que substituir palavras de uma língua para outra. Assim, as modificações que Nath fez no output demonstram que ela utiliza o recurso Google Translator como apoio para construir por ela própria as estruturas da língua inglesa que envia à sua parceira. Conforme afirmam Pica (1994) e Swain (1997, 1999, 2000), Nath utiliza o tradutor para elaborar suas hipóteses, pois ela não transpõe simplesmente a tradução dos termos para a interação, mas reformula o output por meio de seu conhecimento já internalizado, conforme pode ser observado no seguinte excerto.

[9]

[Interação via Openmeetings - 28/08/2010]

Nath: Ah, no. So, do you work in Germany? Do you study (pau- 
sa de 3 segundos) live (pausa de 2 segundos) with two friends, right? Er (pausa de 3 segundos) do you work too?

Eve: [Chat] yes, sometimes i work, not now, but i did several jobs in the past... for example a couple of weeks ago I worked at formula 1 race here in germany... we sold drinks ... are you working, too?

Nath: Oh. my!! You work at Formula 1 race, that's very nice! Yes, I'm working right now (pausa de 3 segundos) not right now at the moment (pausa de 3 segundos) I'm working in (pausa de 2 segundos) my college ((usa o Google Translator durante 22 segundos para traduzir 'laboratório', 'universidade' e tem 'university' 'college'. Em seguida traduz 'laboratório de eventos' e tem 'lab events')).

Eve: [Chat] it's not easy to work and study at the same time here in Germany... so i usually work during the holidays ... in college?

Nath: [Chat] yeah, i work in lab of events

Eve: [Chat] cool, what do you do there?

((usa o Google Translator durante 9 segundos para traduzir: 'eu organizo os eventos da faculdade, eu faço certificado, ligo para recepcionistas' e tem 'I organize the events of college, I do care certificates for receptionists')).

Nath: Well, I organize the events of my college (pausa de 2 segundos) I make certificates (pausa de 3 segundos) I call to receptionists, ham, yeah (pausa de 3 segundos) I think that a, yeah, is this.

Eve: [Chat] that is really nice... do you enjoy it?

Nath, como postula Swain $(1997,1999,2000)$, faz uso do output como um meio para testar as estruturas linguísticas e averiguar se 
estas funcionam ou não no contexto comunicativo dessa interação. Segundo a autora, a elaboração e testagem de hipóteses é um recurso bastante propício à aprendizagem, visto que possibilita ao aprendiz transpor do processamento semântico para o sintático em busca de uma estrutura que vincule, de forma mais precisa, o conteúdo que ele pretende comunicar. Porém, sem negociá-lo com Eve, sua parceira de aprendizagem, para confirmar ou refutar o output, a aprendizagem pode ficar comprometida, bem como o andamento da interação. Na sequência que será apresentada no exemplo 10, observamos que o uso do Google Translator, em detrimento da negociação com Eve, configurou-se, em alguns momentos, como entraves para a fluidez da interação entre o par.

No recorte 10, Nath dá continuidade à interação perguntando sobre os alimentos presentes no almoço de Eve. Nath, buscando informações sobre esses alimentos, utiliza uma estrutura pesquisada no Google Translator para vincular a mensagem. Entretanto, sua parceira alemã não compreende tal estrutura, e solicita a repetição da mensagem, o que acarreta mais uma pesquisa no tradutor eletrônico por Nath. A cada vez que Nath retorna ao Google Translator, os intervalos entre os turnos vão ficando mais longos. Assim, Eve, sem compreender a ausência de Nath, abandona a interação. Nath, por exemplo, só percebeu o último turno de Eve mais de três minutos após a interagente tê-lo enviado. Nesse sentido, parece-nos que, quanto mais Nath insiste em fazer uso apenas do tradutor eletrônico para sanar suas dúvidas, mais confusas as mensagens vão ficando.

Parece-nos que Nath prefere usar o tradutor eletrônico a expor a possibilidade do uso inapropriado da língua à sua parceira e, como resultado, a interação vai esmorecendo. Segundo Crystal (2001), as demoras no retorno de mensagens causam frustrações, e, além disso, o silêncio também causa ambiguidade, pois não há como saber se a 
mensagem chegou ao receptor, se ele está encontrando problemas para compreendê-la ou se optou por não responder a ela, exatamente como ocorreu na interação entre Nath e Eve, ilustrada no exemplo a seguir.

[10]

[Interação via Openmeetings - 28/08/2010]

Nath: [Chat] I said about the typical food in Brazil and the food that i like

Eve: [Chat] hehe that is cool

((usa o Google Translator para traduzir 'então como seria seu prato do almoço?' e tem 'then how would your plate lunch?')).

Nath: How would your plate lunch? at your lunch?

(pausa de 2 minutos)

Eve: [Chat] please, say it again, i did not understand (pausa de 1 minuto e 8 segundos)

Nath: ((consulta o Google Translator novamente e muda a frase para 'como é seu prato do almoço?' obtendo 'how is your plate lunch?'. Digita a frase na barra do chat, apaga parte dela e digita 'how is your plate of lunch', mas não fala/envia a Eve)).

(pausa de 1 minuto e 29 segundos)

Eve: [Chat] are you there ((como a Nath estava demorando para falar, Eve checa se ela ainda estava conectada e, não obtendo resposta, abandona a interação)).

(pausa de 3 minutos e 7 segundos)

Nath: Yeah, yeah, I'm there (pausa de 3 segundos) hãm (pausa de 3 segundos) what is your dish of your lunch? What you frequently eat in your lunch? Hello? I said words wrong, well I'm trying ((Nath ainda permanece conectada à sala de interação por 14 min. Como Eve não retoma a interação, ela deixa a sala)). 
162 Francisco José Q. de Figueiredo and Suelene V. da Silva, Interações...

Nesse exemplo, podemos perceber que Nath, provavelmente por estar insegura em relação ao ambiente de aprendizagem e talvez ao seu próprio conhecimento da língua inglesa, acaba por desconsiderar a aprendizagem colaborativa, que segundo Figueiredo (2006), enfatiza a coconstrução do conhecimento dentro e a partir das interações. Nesse sentido, contar com o apoio do parceiro seria o auxílio mais evidente no processo de aprender línguas em um contexto telecolaborativo de aprendizagem. Nath desconsidera, ainda, os princípios de reciprocidade e de autonomia em contexto de teletandem, já que estes, segundo Vassallo e Telles (2006, 2009), não podem ser interpretados como fazer sozinho, mas, sim, fazer em colaboração com o outro. Nath não compartilha com Eve as suas dúvidas, impossibilitando à sua parceira de contribuir para com sua aprendizagem da língua inglesa. Assim, as ações e atitudes individuais de cada uma das interagentes deveriam ser complementadas pelas da outra, compondo, dessa forma, a identidade de parceria.

$\mathrm{O}$ exemplo a seguir ilustra uma atitude de parceria entre Natalie e Teego. O parceiro alemão, ciente de que poderia contar com a colaboração de Natalie, pesquisa no Google Translator a tradução, em português, do termo que está sendo negociado na interação, que é a palavra 'loser' e até se arrisca a dizer a tradução da palavra em português (perdedor), mesmo não tendo certeza de sua pronúncia. Ao perceber que Natalie compreendeu o que ele havia dito, ele escreve a palavra encontrada no Google Translator para confirmar a palavra pronunciada por ele. Natalie, então, apoia a iniciativa de Teego, dizendo que o termo encontrado no Google Translator está correto, conforme podemos observar no exemplo a seguir.

[Interação via Openmeetings - flvRecording _ 53 - 28/08/2010] 
Natalie: Loser.

Teego: Loser, yeah, and the pronunciation of the 'o' is basically the 'u', Loser.

Natalie: Loser.

Teego: Yeah.

Natalie: But I want to know what is this.

Teego: Ah, I don't know if my translation (pausa de 4 segundos) if it is good from Google.

Natalie: No, no problem. My translation is my Google too, so...

Teego: Per-de-dor (arriscando-se na pronúncia da palavra).

Natalie: Ah, ok, YES, yes... it is the same, yes, perdedor.

Teego: [Chat] perdedor

Natalie: Perdedor, yes, perdedor. Correct.

Teego: Yeah.

Teego e Natalie, diferentemente de Nath e Eve, somam, ao apoio oferecido pelo parceiro, o uso do Google Translator como um recurso auxiliar da aprendizagem de línguas. A atitude de Natalie e Teego de fazer uso de outros recursos, sem desconsiderar o apoio do parceiro, revela o grau de reciprocidade entre eles, o que ilustra o laço de confiabilidade entre o par. Teego acredita no compromisso firmado entre ele e Natalie de que cada um será responsável por auxiliar o outro na aprendizagem da língua de sua competência, o que corrobora o que foi afirmado anteriormente por Benedetti (2010).

O exemplo a seguir ilustra momentos nas interações em que ao áudio e ao chat é acrescido o uso do dicionário eletrônico. Natalie e Teego conversavam sobre comidas típicas do Estado de Goiás. Natalie, após questionar Teego se ele conhecia 'pequi' e receber dele uma resposta negativa, explica-lhe o significado do termo. Mas, o uso do chat e do áudio em torno da temática 'pequi' causa incompreensões 
164 Francisco José Q. de Figueiredo and Suelene V. da Silva, Interações...

na mensagem. É no desenrolar da interação que o uso do dicionário eletrônico ajuda Natalie a esclarecer a mensagem. Para explicar a Teego o que é 'pequi', Natalie se lembra do fato de que é uma fruta que tem espinhos. Assim, ela procura, no dicionário eletrônico, o vocábulo correspondente a 'espinhos' em inglês, já que seu parceiro poderia entender o significado da mensagem, estando a palavra escrita em língua inglesa. Por meio dos recursos disponíveis pelo Openmeetings, bem como os que a ele são associados, os interagentes compartilham informações linguísticas e culturais que servem de apoio para a aprendizagem de seu parceiro, como ilustrado a seguir.

[Interação via Openmeetings - flvRecording _ 73 - 04/09/2010]

Natalie: And have you ever known about 'pequi'?

Teego: 'Pequi'? No.

Natalie: It is a typical food here in Goiás, in Goiânia (pausa de 2 segundos) and all the State of Goiás, is very good.

Teego: But what is it (pausa de 4 segundos) what is it like?

Natalie: Is?

Teego: What is it like? What is it, actually?

Natalie: It is, it is for you have lunch, when you almoça, have lunch. It is uhmm (pausa de 4 segundos) salt, but it has... ((verifica no dicionário <http://translito.com> a tradução de 'espinhos')).

I don't know the pronunciation, but I think is 'thorns'.

Natalie: [Chat] thorns

Teego: 'Thorns'?

Natalie: With...

Teego: Like in a rose, like the flower of a rose? It's 'thorns', as well as (pausa de 3 segundos) I think. Yep. Can you write the really name for the 'pequi'? 
Natalie: [Chat] espinhos.

Teego: 'Espinhos'?

Natalie: 'Espinhos' is 'thorns'. How can you pronounce this word?

Natalie: [Chat] Pequi.

Teego: Pequi ((lendo o chat)).

Teego: 'Thorns' ((atendendo à solicitação da pronúncia)).

Natalie: 'Thorns', it is. 'Pequi' has 'thorns'.

Teego: Ok.

Os exemplos aqui discutidos evidenciam que a alternância de papéis entre os interagentes brasileiros e os estrangeiros ocorria naturalmente no desenrolar das interações: os participantes brasileiros desempenhavam o papel de aprendizes de língua inglesa e de informantes quanto à cultura brasileira. Os participantes estrangeiros, por sua vez, eram ora aprendizes de português e da cultura brasileira, ora auxiliares de seus parceiros no processo de aprendizagem do inglês. Essa alternância de papéis dos interagentes revela o princípio da reciprocidade do teletandem. Esse princípio em consonância com o princípio de autonomia, somado ao uso dos recursos presentes e associados ao aplicativo Openmeetings, potencializa mudanças qualitativas no processo de aprender uma LE. Nesse sentido, o ambiente virtual configura-se como um contexto bastante profícuo para a coconstrução do processo de aprendizagem de línguas, não só na modalidade teletandem, mas também em outras modalidades que assumem a aprendizagem colaborativa como pilar desse processo.

\section{Considerações finais}

Os resultados deste estudo sugerem que um elemento bastante influenciador em interações telecolaborativas é o modo como os in- 
teragentes percebem e lidam com o aplicativo computacional escolhido para mediar o processo de aprendizagem de línguas. No caso deste estudo, por exemplo, observamos que, durante as interações, tanto os interagentes brasileiros quanto os alemães fizeram uso de alguns dos recursos presentes e de outros associados ao aplicativo Openmeetings para auxiliá-los na realização das interações. Quanto aos recursos que são parte do aplicativo, observamos o uso de áudio, vídeo, chat e lousa interativa. Quanto aos recursos associados, os interagentes utilizaram o Google Translator e dicionários eletrônicos.

O áudio e o vídeo são os recursos primários do aplicativo Openmeetings e é por meio deles que os interagentes podem falar e ouvir seus parceiros, bem como vê-los por meio da webcam. Estes também são os recursos que aproximam a aprendizagem de línguas em teletandem de interações realizadas face a face, pois o uso da webcam associado aos demais recursos disponíveis no contexto de aprendizagem em ambiente virtual possibilita aos aprendizes sentir-se como se estivessem no mesmo ambiente físico de seus parceiros. Tal sensação contribui também para que haja uma aproximação entre os próprios parceiros, fortalecendo laços de amizade e a construção de uma identidade de parceria.

Afirmamos, com base nos resultados já discutidos, que a opção por um ou por outro recurso é afetada pelo próprio ambiente virtual, pois alguns recursos podem apresentar problemas de funcionamento, e pelas próprias atitudes dos interagentes. Desse modo, em termos gerais, são as escolhas dos interagentes, agregadas à disponibilidade de um ou de outro recurso, que delineiam a sessão de interação, pois os recursos integrados ao aplicativo estão à disposição do aprendiz, mas o uso deles depende, além de condições técnicas favoráveis, da atitude do interagente. É, portanto, o grau de autonomia desse aprendiz em relação aos recursos disponíveis no aplicativo que possibilita 
a ele próprio e a seu parceiro transformar as formas de auxilio que os recursos digitais propiciam em favor da aprendizagem de línguas, ampliando qualitativamente as oportunidades de aprendizagem da modalidade teletandem. Assim, ao engajar-se em atividades telecolaborativas, o aprendiz não se torna responsável apenas pela própria aprendizagem, visto que ele também passa a colaborar com a aprendizagem de seu parceiro. Nesse sentido, suas tomadas de decisão em relação aos procedimentos de desenvolvimento do processo de aprendizagem, como, por exemplo, fazer uso ou não de recursos auxiliares à aprendizagem, pode influenciar diretamente na sua aprendizagem e na de seu parceiro.

Afirmamos, igualmente, que a negociação entre os participantes deste estudo foi sendo tecida pela oralidade, pela escrita e pela representação da mensagem por meio de desenhos, conforme a escolha dos próprios interagentes do uso de um ou de outro recurso do aplicativo Openmeetings. Nesse sentido, a opção dos interagentes por congregar o uso do áudio aos demais recursos disponibilizados pelo aplicativo Openmeetings (vídeo, chat, lousa interativa) foi bastante positiva, pois contribuiu para que as interações mantivessem a dinamicidade, já que muitas das incompreensões nas mensagens foram solucionadas pelo uso concomitante desses recursos.

Entretanto, os recursos que foram associados ao aplicativo, como, por exemplo, o Google Translator, nem sempre apresentaram uma perspectiva favorável à aprendizagem em teletandem. A opção pelo Google Translator, por exemplo, no caso de Nath, em alguns momentos prejudicou a negociação com o parceiro. Podemos afirmar, com base nos resultados deste estudo, que o recurso em si não possui poder de alterar nenhum fluxo da ação. O uso que o indivíduo faz da ferramenta é que resulta em uma ou outra nova ação. Natalie e Teego, por exemplo, tiveram mais êxito no uso do Google Translator 
e dos dicionários on-line em diferentes momentos da interação.

Conforme observamos, o aplicativo Openmeetings possui todas as características necessárias para desempenhar bem as sessões de aprendizagem em um contexto virtual por proporcionar comunicação síncrona de mensagens instantâneas, por meio da utilização dos recursos de escrita, leitura, e videoconferência. O aplicativo é gratuito, está disponível para download na rede e permite a associação a outros aplicativos. Nessa perspectiva, os recursos do aplicativo e os associados a ele ampliam as oportunidades de uso das línguas, visto que os aprendizes podem ter acesso a diferentes meios para aprender e se fazer compreendidos na LE.

Por fim, a colaboração, em ambientes presenciais ou virtuais, é um conceito importante no processo de aprendizagem de línguas, pois enfatiza a questão da mutualidade da aprendizagem na realização de atividades, bem como de uma maior significação nos relacionamentos humanos. Cabe, então, a nós, professores, proporcionar oportunidades aos alunos de se engajarem em atividades nas quais tenham a oportunidade de interagir significativamente e que, através da interação e da colaboração, possam aprender ainda mais uns com os outros, podendo contar, também, com o apoio da tecnologia a favor dessa aprendizagem.

\section{Referências}

AIKEN, M.; BALAN, S. An analysis of Google translate accuracy. Translation Journal. v. 16, n. 2, p. 1-3, 2011. Disponível em: <http://translationjournal.net/journal/56google.htm>. Acesso em: 23 jan. 2012.

BENEDETTI, A. M. Dos princípios de tandem ao teletandem. In: BENEDETTI, A. M.; CONSOLO, D. A.; VIEIRA-ABRAHÃO, M. H. V. (Org.). Pesquisas em ensino e aprendizagem no teletandem Brasil: línguas estrangeiras para todos. Campinas, S.P.: Pontes Editores, 2010. p. 21-45. 
BOGDAN, R.; BIKLEN, S. Investigação qualitativa em educação: uma introdução à teoria e aos métodos. Porto: Porto Editora, 1994.

CAVALARI, S. M. S. As definições das metas e o processo de autoavaliação no contexto teletandem. In: BENEDETTI, A. M.; CONSOLO, D. A.; VIEIRA-ABRAHÃO, M. H. V. (Org.). Pesquisas em ensino e aprendizagem no teletandem Brasil: línguas estrangeiras para todos. Campinas, S.P.: Pontes Editores, 2010. p. 329-347.

CRYSTAL, D. Language and the internet. Cambridge: Cambridge University Press, 2001.

. English as a global language. Cambridge: Cambridge University Press, 2003.

DONATO, R.; MCCORMICK, D. A sociocultural perspective on language learning strategies: the role of mediation. The Modern Language Journal, v. 78, n. 4, p. 453-464, 1994.

FERNANDES, F. R.; CONSOLO, D. A. A questão tecnológica no teletandem: entraves e possíveis soluções. In: BENEDETTI, A. M.; CONSOLO, D. A.; VIEIRA-ABRAHÃO, M. H. V. (Org.). Pesquisas em ensino e aprendizagem no teletandem Brasil: línguas estrangeiras para todos. Campinas, S.P.: Pontes Editores, 2010. p. 65-87.

FIGUEIREDO, F. J. Q. de. A aprendizagem colaborativa de línguas: algumas considerações conceituais e terminológicas. In: FIGUEIREDO, F. J. Q. de. (Org.). A aprendizagem colaborativa de línguas. Goiânia: Editora da UFG, 2006. p. 11-45.

HÖFLING, C.; SILVA, M. C. P. da; TOSQUI, P. Técnicas de utilização de dicionário como material didático na aula de LE para fins específicos. Revista Brasileira de Linguística Aplicada, v. 6, n. 1, p. 51-64, 2006.

LEFFA, V. J. Interação simulada: um estudo da transposição da sala de aula para o ambiente virtual. In: LEFFA, V. J. (Org.). A interação na aprendizagem de línguas. Pelotas: EDUCAT, 2006. p. 175-212. Disponível em: $<$ http://www.leffa.pro.br/textos/trabalhos/simulada.pdf $>$. Acesso em: 06 jan. 2012.

PAIVA, V. L. M. de O. e. A WWW e o ensino de inglês. Revista Brasileira de Linguística Aplicada, v. 1, n. 1, p. 93-116, 2001. 
PICA, T. Research on negotiation: what does it reveal about second-language learning conditions, processes, and outcomes? Language Learning, v. 44, n. 3, p. 493-527, 1994.

SILVA, S. V. da. O processo ensino-aprendizagem de línguas em teletandem: um estudo na área de Turismo. 2012. 293 f. Tese (Doutorado em Letras e Linguística) - Faculdade de Letras, Universidade Federal de Goiás, Goiânia, 2012.

SANTOS, G. R. dos. O que acontece durante as interações de teletandem: investigando os dados. In: TELLES, J. A. (Org.). Teletandem: um contexto virtual, autônomo e colaborativo para aprendizagem de línguas estrangeiras no século XXI. Campinas, S.P.: Pontes Editores, 2009. p. 123-147.

SOUZA, R. A. de. Telecolaboração e divergência em uma experiência de aprendizagem de português e inglês como línguas estrangeiras. Revista Brasileira de Linguística Aplicada, v. 3, n. 2, p. 73-96, 2003.

. Telecolaboração na aprendizagem de línguas estrangeiras: um estudo sobre o regime de tandem. In: FIGUEIREDO, F. J. Q. de. (Org.). A Aprendizagem Colaborativa de Línguas. Goiânia: Editora da UFG, 2006. p. 255-276.

SWAIN, M. The functions of output in second language learning. In: COOK, G.; SEIDELHOFER, B. (Ed.). Principle and Practice in Applied Linguistics: studies in honor of H. G. Widdowson. Oxford: Oxford University Press, 1997. p. 115-132.

Integrating language and content: teaching through collaborative tasks. Canadian Modern Language Review, v. 52, n. 4, p. 44-63, 1999. Disponível em: <http://tesl.tcnj.edu/PDF\%20Resources/EJ635196\%20 Mainstreming\%20ESL\%20Learners.pdf>. Acesso em: 22 jun. 2011.

. The output hypothesis and beyond: mediating acquisition through collaborative dialogue. In: LANTOLF, J. P. (Ed.). Sociocultural theory and second language learning. Hong Kong: Oxford University Press, 2000. p. 97-114.

TELLES, J. A. Teletandem: conceito e ações para a prática e pesquisa. In: TELLES, J. A. (Org.). Teletandem: um contexto virtual, autônomo e colaborativo para aprendizagem de línguas estrangeiras no século XXI. Campinas, S.P.: Pontes Editores, 2009a. p. 17-18. 
. Teletandem: metamorfoses impostas pela tecnologia sobre o ensino de línguas estrangeiras. In: TELLES, J. A. (Org.). Teletandem: um contexto virtual, autônomo e colaborativo para aprendizagem de línguas estrangeiras no século XXI. Campinas, S. P.: Pontes Editores, 2009b. p. 63-74.

VASSALLO, M. L. Teletandem ou tandem presencial? In: TELLES, J. A. (Org.). Teletandem: um contexto virtual, autônomo e colaborativo para aprendizagem de línguas estrangeiras no século XXI. Campinas, S.P.: Pontes Editores, 2009. p. 93-119.

VASSALLO, M. L.; TELLES, J. A. Foreign language learning in-tandem: Teletandem as an alternative proposal in CALLT. The ESPecialist, v. 27, n. 2, p. 189-212, 2006.

. Ensino e aprendizagem de línguas em tandem: princípios teóricos e perspectivas de pesquisa. In: TELLES, J. A. (Org.). Teletandem: um contexto virtual, autônomo e colaborativo para aprendizagem de línguas estrangeiras no século XXI. Campinas, S.P.: Pontes Editores, 2009. p. 21-42.

VYGOTSKY, L. S. The development of higher forms of attention in childhood. In.: WERTSCH, J. V. (Ed.). The concept of activity in Soviet Psychology. New York: M.E. Sharpe, 1981. p. 144-240.

. A formação social da mente: o desenvolvimento dos processos psicológicos. São Paulo: Martins Fontes, 1998.

WARSCHAUER, M. Computer Assisted Language Learning: an Introduction. In: FOTOS, S. (Ed.). Multimedia language teaching. San Francisco: Logos International, 1996. p. 3-20.

(Recebido em 30/03/14. Aceito em 15/05/14) 
